\title{
Review Article \\ Vitamin D: A Review on Its Effects on Muscle Strength, the Risk of Fall, and Frailty
}

\author{
Matthieu Halfon, Olivier Phan, and Daniel Teta \\ Service of Nephrology, Department of Medicine, Centre Hospitalier Universitaire Vaudois (CHUV), Lausanne, Switzerland \\ Correspondence should be addressed to Matthieu Halfon; matthieu.halfon@chuv.ch
}

Received 31 October 2014; Revised 1 March 2015; Accepted 1 March 2015

Academic Editor: Germán Vicente-Rodriguez

Copyright ( 2015 Matthieu Halfon et al. This is an open access article distributed under the Creative Commons Attribution License, which permits unrestricted use, distribution, and reproduction in any medium, provided the original work is properly cited.

\begin{abstract}
Vitamin D is the main hormone of bone metabolism. However, the ubiquitary nature of vitamin D receptor (VDR) suggests potential for widespread effects, which has led to new research exploring the effects of vitamin D on a variety of tissues, especially in the skeletal muscle. In vitro studies have shown that the active form of vitamin $\mathrm{D}$, calcitriol, acts in myocytes through genomic effects involving VDR activation in the cell nucleus to drive cellular differentiation and proliferation. A putative transmembrane receptor may be responsible for nongenomic effects leading to rapid influx of calcium within muscle cells. Hypovitaminosis D is consistently associated with decrease in muscle function and performance and increase in disability. On the contrary, vitamin D supplementation has been shown to improve muscle strength and gait in different settings, especially in elderly patients. Despite some controversies in the interpretation of meta-analysis, a reduced risk of falls has been attributed to vitamin D supplementation due to direct effects on muscle cells. Finally, a low vitamin D status is consistently associated with the frail phenotype. This is why many authorities recommend vitamin D supplementation in the frail patient.
\end{abstract}

\section{Introduction}

Vitamin D is the main hormone regulating calcium phosphate homeostasis and mineral bone metabolism. The discovery that a variety of tissues can express vitamin $\mathrm{D}$ receptor (VDR) has opened new ways of research related to vitamin $\mathrm{D}$ biological effects and molecular pathways [1-3]. There is evidence that vitamin $\mathrm{D}$ is implicated in the regulation of the immune system, the cardiovascular system, oncogenesis [4], and cognitive functions [5].

Loss of muscle mass and frailty are prevalent in many chronic diseases such as chronic obstructive pulmonary disease, cardiac insufficiency, cancer, and chronic kidney disease (CKD) [6].

Vitamin D deficiency is indeed extremely frequent in the above diseases. More than 3 decades ago, the clinical observation that patients with rickets and osteomalacia displayed proximal myopathy suggested a direct link between hypovitaminosis D and muscle function [7]. Recent evidence has confirmed that vitamin D may modulate muscle growth. In this review, we will specifically address the effect of vitamin
D on skeletal muscles and its clinical implications, especially frailty and the risk of fall.

\section{Methods}

This is a review article not intended to meet the full range of criteria required for a systematic review. However, we used a rigorous methodology for the selection of the material presented here. In October 2014, we performed a comprehensive literature search in the bibliographic database "Pubmed," looking at studies discussing the following topics: "hypovitaminosis D and physical performance: observational studies," "can vitamin D supplementation improve muscle function?" "relationship between vitamin D status, muscle and falls," and "link between vitamin D and frailty." The study period considered was from January 1, 2000, to September 30, 2014. Keywords used were "vitamin D," "muscle," "strength," "fall," "frailty," "risk," "chronic kidney disease," "supplementation," "randomized controlled trial," "review," "systematic review," and "meta analysis." Only articles in English were considered. From the studies identified in this way, we selected only 
observational trials, randomized control trials (RCTs), and meta-analysis. Case reports and series were excluded. In studies testing vitamin D supplementation, the dose of vitamin D should have been specified, physical performance/gait should have been reported by objective measurements, and blood level of vitamin D should have been reported. In studies regarding frailty, the terminology of frailty should have been defined by objective criteria. Finally, we did not include the totality of studies meeting the above criteria, in order to prevent redundancies. Studies confirming results from previous relevant studies and providing similar conclusions were voluntarily not cited.

\section{Vitamin D Metabolism}

Vitamin D metabolism is orchestrated by the skin, the liver, and the kidney. The role of sun exposure is instrumental since UVB-induced vitamin D3 production in the skin accounts for $80-90 \%$ of vitamin D formation, whereas nutritional intake (fatty fish, eggs, fortified milk, and plants) only accounts for $10-20 \%$ of vitamin D3 provision. UVB converts 7-dehydrocholesterol to previtamin D which is then converted to cholecalciferol (or vitamin D3). Cholecalciferol subsequently binds to vitamin D binding globulin and this complex is transported to the liver where it is hydroxylated in 25-hydroxyvitamin D3 (or 25(OH) D3), the major circulating form. 25-Hydroxyvitamin D3 undergoes a final hydroxylation in the kidney proximal tubule in order to produce 1,25 dihydroxyvitamin D3 or calcitriol, the biologically active form [8]. The 1-hydroxylation is stimulated by the parathyroid hormone (PTH) and inhibited by the Fibroblast Growth Factor 23 (FGF-23). Calcitriol interacts with vitamin D receptor (VDR) in the cell nucleus to mediate biological effects through activation of calcium channels. Vitamin D synthesis depends on environmental factors such as sunlight exposure and sun cream application [9] and biologic factors such as skin's pigmentation and kidney function. In elderly people, dietary vitamin D (vitamin D2 from plants and vitamin D3 from animals) may become the major source of vitamin D3 because of reduced 7-dehydrocholesterol concentration [10] and impaired hydroxylation in the liver and the kidney [11]. This is why the relevance of vitamin D status is highlighted in this population. This is particularly true for the elderly frail patient clinically characterized by a low nutritional intake and muscle loss. Whether vitamin $\mathrm{D}$ deficiency may aggravate muscle function and frailty is thus a very important question.

\section{Vitamin D Deficiency and Insufficiency}

Because of unregulated hydroxylation by the liver, 25hydroxyvitamin $\mathrm{D}$ is used as the marker of vitamin $\mathrm{D}$ status. Low levels of serum vitamin D (25-hydroxyvitamin D) may define vitamin $\mathrm{D}$ deficiency versus insufficiency [12]. However, the definitions of low levels of vitamin D vary among authors and nutritional societies/authorities. For some authors, vitamin D deficiency is the level below which osteomalacia may appear [13]. In general, this occurs at a concentration below $25 \mathrm{nmol} / \mathrm{L}$ [12]. Vitamin D insufficiency may be defined as the level below which PTH begins to rise.
Depending on the studies, this level may vary from 25 to $75 \mathrm{nmol} / \mathrm{L}$. Another definition is only based on serum concentration thresholds without considering biological or clinical abnormalities [14]. According to this definition, vitamin D status may be divided into 4 group levels: severe deficiency defined by a concentration of less than $27.5 \mathrm{nmol} / \mathrm{L}$, deficiency between 27.5 and $49.9 \mathrm{nmol} / \mathrm{L}$, insufficiency between 50 and $75 \mathrm{nmol} / \mathrm{L}$, and optimal above $75 \mathrm{nmol} / \mathrm{L}[15,16]$. Differences of definitions between authors may explain, at least in part, conflicting resulting from meta-analysis addressing vitamin $\mathrm{D}$ status and outcomes. Vitamin D deficiency/insufficiency is highly prevalent but the magnitude of hypovitaminosis D may vary depending on the population studied and regional and seasonal considerations. We will only comment on examples of prevalence in the elderly population. Among healthy elderly patients in Argentina, Oliveri et al. found prevalence between $52 \%$ and $87 \%$ of vitamin D insufficiency (serum level below $50 \mathrm{nmol} / \mathrm{L}$ ) in the winter depending on the latitude [17]. In another study addressing institutionalized elderly patients from Buenos Aires, $41 \%$ of the residents had a vitamin $\mathrm{D}$ serum level of less than $25 \mathrm{nmol} / \mathrm{L}$ [10]. In a study looking at elderly Italian women, the prevalence of low vitamin $\mathrm{D}$, defined as a serum level below $30 \mathrm{nmol} / \mathrm{L}$, was $51 \%$ in the December-May period and $17 \%$ in the June-November period [18].

\section{Vitamin D and the Skeletal Muscle: Molecular Pathways}

Vitamin D receptors (VDR) are expressed in a large number of human cell types, including skeletal muscle cells, indicating the potential for widespread effects $[2,19,20]$. Two mechanisms by which vitamin D may act in skeletal muscle have been proposed (Figure 1). VDR acts as a nuclear receptor which mediates the so-called genomic effects; VDR also acts via nonnuclear receptor mediating nongenomic actions. Genomic effects have been well characterized in studies in vitro $[8,21]$. VDR is a ligand-dependent transcription factor, which belongs to the steroid-thyroid hormone receptor gene superfamily. Once transported in the nucleus by an intracellular binding protein, calcitriol binds to its nuclear receptor which results in gene transcription and subsequent de novo protein synthesis. At the nuclear level, the activation of VDR induces heterodimerization between the active VDR and the retinoic receptor (RXR). This leads to the activation of the vitamin D response element (VDRE), a complex of genes coding for the "genomic effects" of vitamin D. Genomic effects of VDR include the increase in calcium handling by enhancing the activities of the calcium binding protein (calbindin-D9K) in cell sarcoplasm [22,23], muscle cell differentiation and proliferation through effects on insulin growth factor expression which in turn induces skeletal muscle hypertrophy [24]. Mechanisms leading to vitamin D nongenomic effects are not definitely elucidated. 1,25 vitamin $\mathrm{D}$ appears to bind a membrane receptor which activates a transduction signal inducing MAP kinase (MAPK) and phospholipase C (PLC) pathways, which in turn lead to a rapid influx of calcium into the cell $[8,21]$. The origin of this 


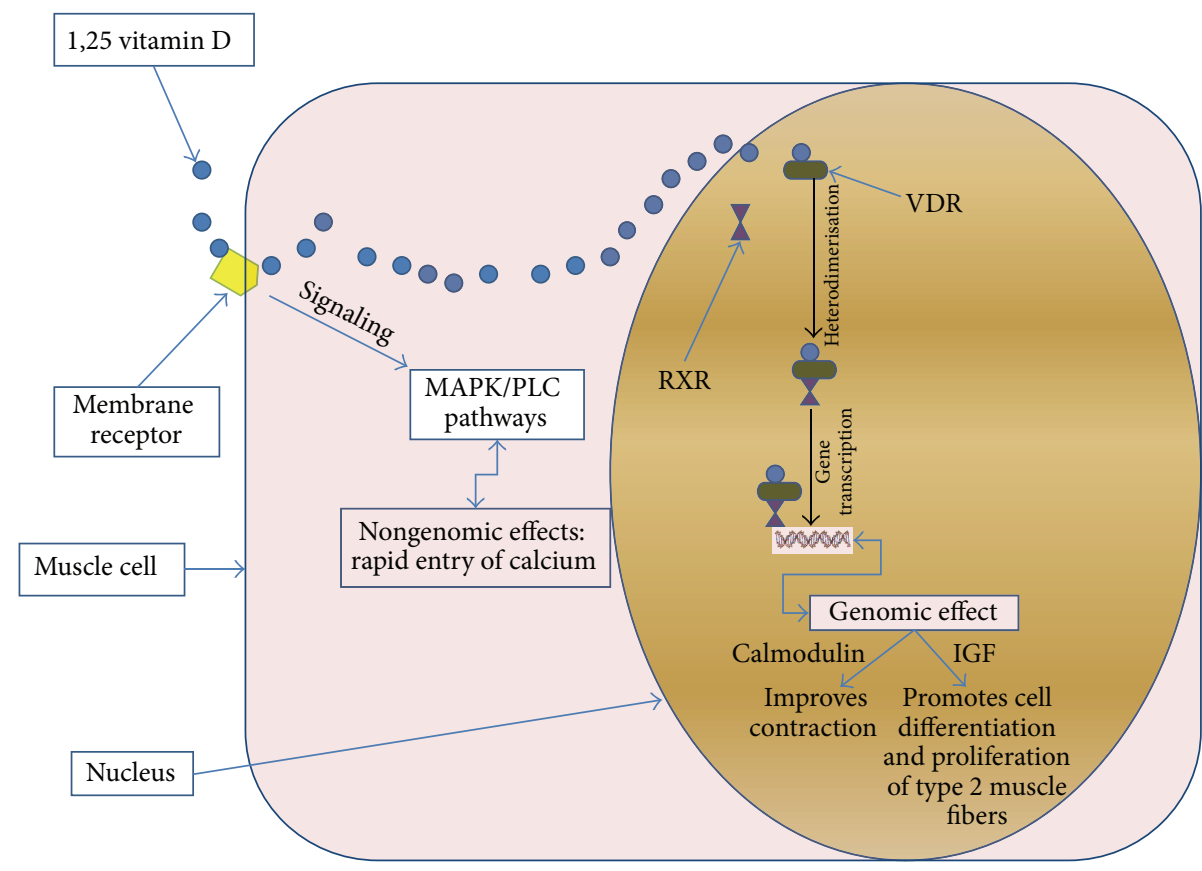

FIGURE 1: Effects of 1,25 vitamin D on muscle cells: molecular and nuclear pathways. 1,25 vitamin D binds the vitamin D receptor (VDR) in the nucleus, where it forms a complex with the retinoid receptor (RXR). The complex 1,25 vitamin D/VDR/XDR activates gene transcription, leading to known genomic effects. On the other hand, 1,25 vitamin D binds a putative membrane receptor which activates MAP kinase (MAPK) and phospholipase C (PLC) pathways leading to nongenomic effects.

membrane receptor is controversial. Some authors claimed that this membrane receptor is the intranuclear VDR receptor itself, which translocates from the nucleus to the plasma membrane, while others suggest that this is a distinct receptor $[25,26]$. Some studies have explored vitamin D molecular pathways and VDR, through vitamin D supplementation. For instance, Ceglia et al. showed that, in elderly women, a supplementation of vitamin D (4000 IU/day) during 4 months was associated with a $30 \%$ increase in intramyonuclear VDR concentration and a $10 \%$ increase in muscle fiber crosssectional area, especially type 2 fibers [27]. The VDR has several polymorphisms, some of which may have clinical significance. Geusens et al. showed that the presence (allele bb) or absence (allele BB) of a restriction fragment (BsmI) may determine muscle strength; that is, subjects with the bb phenotype had 23\% higher muscle strength in the quadriceps than those with the BB phenotype [28].

\section{Hypovitaminosis D and Physical Performance: Observational Studies}

Many observational studies have investigated clinical relationships between vitamin $\mathrm{D}$ serum concentration and physical performance. In the Invecchiare in Chianti (InCHIANTI) study (966 individuals, 435 men and 531 women) with a mean age of 75 years, a significant association between low levels of vitamin D and poor physical performance as assessed by the handgrip strength test and a short physical performance battery test (ability to stand from a chair and ability to maintain balance in progressively more challenging positions) was found [29]. Individuals with serum vitamin $\mathrm{D}$ below $25 \mathrm{nmol} / \mathrm{L}$ performed lower than those with a level above $25 \mathrm{nmol} / \mathrm{L}$. Muscle strength using a handgrip test was also significantly greater in subjects with vitamin D levels higher than $50 \mathrm{nmol} / \mathrm{L}$ than in those with levels below this threshold [29]. Mastaglia et al. reported that, in healthy women aged over 65 years $(n=54)$, vitamin D levels above $50 \mathrm{nmol} / \mathrm{L}$ were associated with a higher muscle strength from lower limbs (stronger knee extensor of $13.4 \pm 2.7$ versus $11.6 \pm 2.5 \mathrm{~kg}, P<0.03)$ [30]. Zamboni et al. measured serum vitamin D in elderly women $(n=175)$ and men $(n=94)$ and disability was self-reported using different questionnaires. Individuals reporting disability had a lower serum vitamin D level than those without self-reported disability [31]. This observation was confirmed in the Longitudinal Aging Study Amsterdam (LASA) prospective study which followed 1200 elderly men and women (600 men and 634 women) during 3 years. A physical assessment was performed at baseline and after 3 years. Subjects with vitamin D serum levels below $25 \mathrm{nmol} / \mathrm{L}$ had a greater chance of showing a decline in physical performance, defined by a change in the EdwardsNunnally Index, than those with levels higher than $75 \mathrm{nmol} / \mathrm{L}$ (OR: 2.21, 95\% CI 1.00-4.87) [32]. Using data from the same cohort, Visser et al. demonstrated that elderly individuals with a low vitamin D level $(<25 \mathrm{nmol} / \mathrm{L})$ had a 2.5 -fold increase in the risk of developing sarcopenia, defined as a loss of handgrip strength of more than $40 \%$ or a loss of muscle mass of more than 3\%, in a 3-year time period, compared with those with levels of $>50 \mathrm{nmol} / \mathrm{L}$ [33]. In a study investigating 
elderly patients with falls (230 men and 370 women), a higher serum concentration of vitamin $\mathrm{D}$ was associated with a 3 times faster "time and get up" (TUG) test (i.e., the time required for the patient to stand up from a standard chair, walk a distance of 3 meters, turn around, walk back to the chair, and sit down again), with a five times faster "sit to stand" test in men, and with a 2.5 times faster TUG test in women. The data suggest possible differences in the effects of vitamin D according to the gender [34]. However, in the Progetto Veneto Anziani (Pro.V.A) study, which included 2694 community-dwelling elderly patients (1597 females and 1097 males, mean age of 74 years, $40 \%$ of women and $20 \%$ of men with a serum vitamin D below $50 \mathrm{nmol} / \mathrm{L}$ ), it was shown that lower vitamin D levels were associated with a lower 6minute walking test and weaker strength, independently of gender [35]. Positive effects of vitamin D reserves are not only observed in older persons. In a study including 1000 healthy European adolescents (470 males and 530 females), handgrip test performance was positively associated with vitamin $\mathrm{D}$ levels in females [3]. In another study including young women (age between 19 and 29 years), there was a correlation between vitamin $\mathrm{D}$ level and the handgrip test in both dominant and nondominant arms [36]. An additional study in healthy men $(n=205)$ and women $(n=214)$ (mean age of 43 years) showed a relationship between vitamin $D$ and isometric/isokinetic arm strengths in multivariate analysis [37]. In the particular setting of CKD, 3 small studies, one study in CKD treated conservatively and 2 studies in dialysis patients, suggest a positive relationship between vitamin $\mathrm{D}$ status and functional ability [38-40].

A few studies did not confirm an association between vitamin D status and physical performances. Pramyothin et al. performed a study in older Hawaii women of Japanese ancestry, a population known for its very low rate of falls, a high dietary intake in vitamin $\mathrm{D}$, and a large exposure to sunlight [41]. In this population, mean vitamin D level was $80 \mathrm{nmol} / \mathrm{L}$ and no subject presented vitamin D deficiency. There was no relationship between vitamin $\mathrm{D}$ level, physical strength test (except for the quadriceps), falls, and daily activities. The authors conclude that the absence of relationship was due to the very high level of vitamin D at baseline. In addition, another study in young men (mean age of 47 years) from Ceglia et al. including more than 1000 individuals did not demonstrate a link between vitamin $\mathrm{D}$ levels and physical performances [42]. However, only $20 \%$ of the subjects had a vitamin D level below $50 \mathrm{nmol} / \mathrm{L}$ [42]. These 2 negative studies, along with other observations, suggest the existence of a threshold in vitamin $\mathrm{D}$ level, below which hypovitaminosis $\mathrm{D}$ may negatively affect muscle function $[29,30]$. However, in one study including 367 elderly individuals aged more than 80 years with $80 \%$ prevalence in vitamin D insufficiency, there was again no relationship between vitamin $\mathrm{D}$ level and physical performance, as assessed by gait speed, hand grip test, and a static balance test. In this case, the authors explain the absence of association by the decrease in VDR expression observed in very old individuals [43].

To sum up, most of the observational studies report a significant association between hypovitaminosis $\mathrm{D}$ and muscle dysfunction in all categories of ages, except in very old individuals. On the contrary, vitamin D levels greater than $50 \mathrm{nmol} / \mathrm{L}$ are associated with the lowest probability of muscle dysfunction. Some studies suggest that gender may influence the association between vitamin $\mathrm{D}$ and skeletal muscle function.

\section{Can Vitamin D Supplementation Improve Muscle Function?}

Several RCTs and meta-analyses have investigated the effect of vitamin D supplementation on muscle function. Two RCTs in Asians, one in healthy young volunteers [44] and another one in elderly women, compared the supplementation of daily or weekly (Table 1) vitamin D combined with calcium versus calcium alone or placebo [11]. These studies reported a benefit of vitamin D supplementation during 3 to 6 months on muscle function, that is, an improvement in quadriceps strength as measured by an isokinetic dynamometer device [11] and an improvement in 6 min walk test [44]. Another trial in 300 elderly women with a level of vitamin $\mathrm{D}<60 \mathrm{nmol} / \mathrm{L}$ demonstrated a benefit with a daily supplementation of 2000 IU of vitamin D on the TUG test. The subjects from the lowest quartile had an additional improvement in muscular strength [45]. Benefits of vitamin D supplementation were also shown in teenager females. Ward et al. randomized 69 postmenarchal females to receive either 4 doses of 150,000 IU of vitamin D2 or placebo, over one year. In the interventional group, mean vitamin $\mathrm{D}$ level was greater than $50 \mathrm{nmol} / \mathrm{L}$ and this was associated with improved jump velocity [46]. Another small interventional trial including young elite ballet dancers (11 males and 13 females, mean age: 28) showed an improved isometric strength and less injuries in the group receiving a daily dose of $2000 \mathrm{IU}$ vitamin D [47]. In contrast, 2 trials did not show a benefit of vitamin D supplementation [48, 49]. However, one of these studies included healthy men, with very good physical performance at baseline and without vitamin D deficiency/insufficiency [48]. In the other study, vitamin $\mathrm{D}$ was administrated at a lower dose, that is, $8400 \mathrm{IU}$ of vitamin D3 once weekly, and this failed to improve physical performance, but in the latter study, there was a positive effect on balance in a subgroup of patients with markedly low balance at baseline [49]. Two additional RCTs using intermittent large amounts of vitamin D did not show a benefit on physical performance [50-53]. One study tested the effect of 150,000 IU of cholecalciferol every 3 months in 689 elderly women (mean age above 76 years) for 9 months. Muscle strength was assessed at baseline and every 3 months with a dynamometer, and mobility was measured by a TUG test [52]. There was no difference between the treatment and the control groups. However, vitamin D was measured in only 40 subjects of the 700 subjects with indeed a high baseline level $(65.8 \mathrm{nmol} / \mathrm{L})$. In the other study, 173 young healthy females (mean age of 21 years) were given a supplementation of 60,000 IU of cholecalciferol, once a week for 8 weeks, and then 60,000 IU every 2 months for 4 months. There was no difference in muscle strength at 6 months. These findings suggest that intermittent high doses of vitamin D may not be effective at improving muscular strength. This 


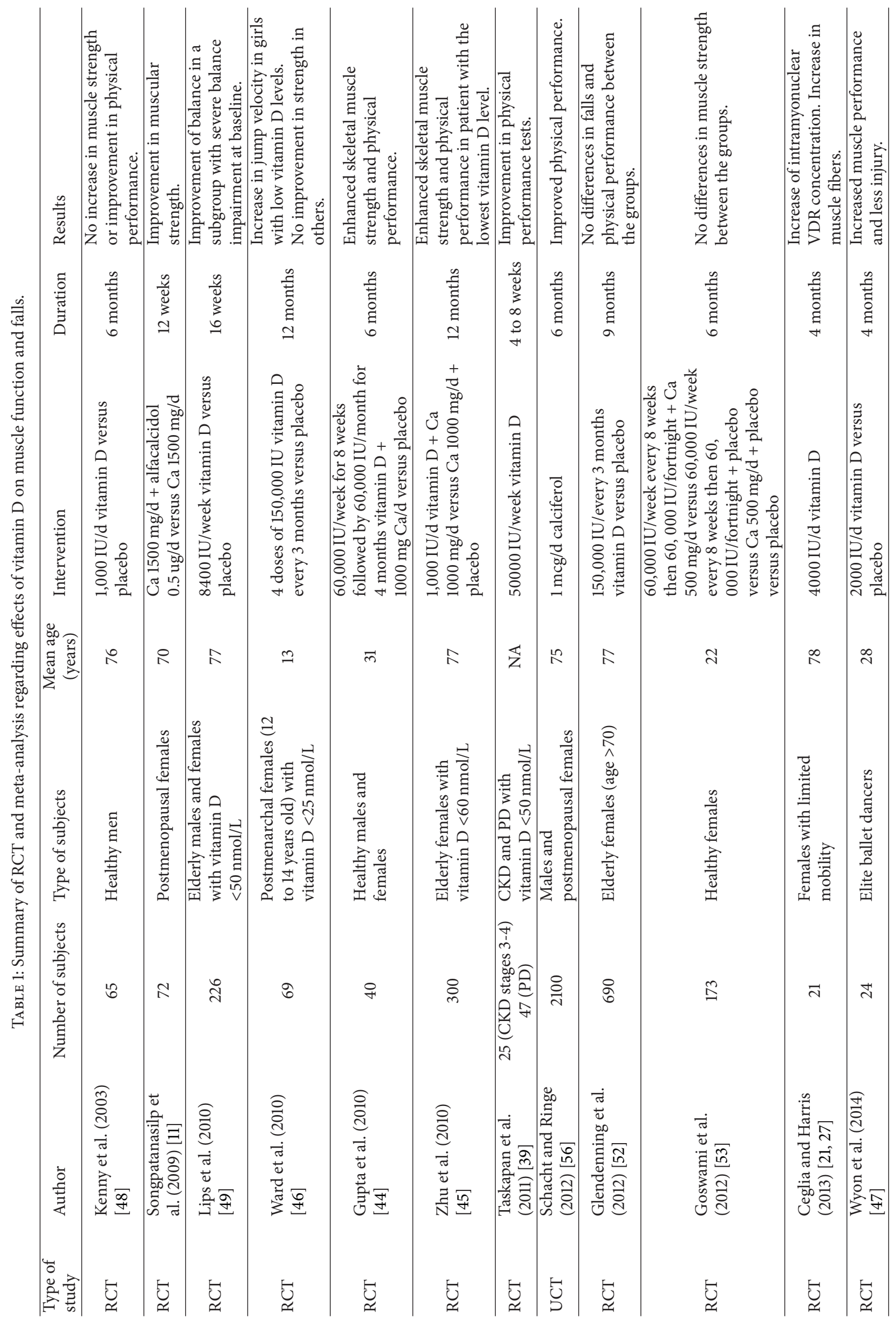




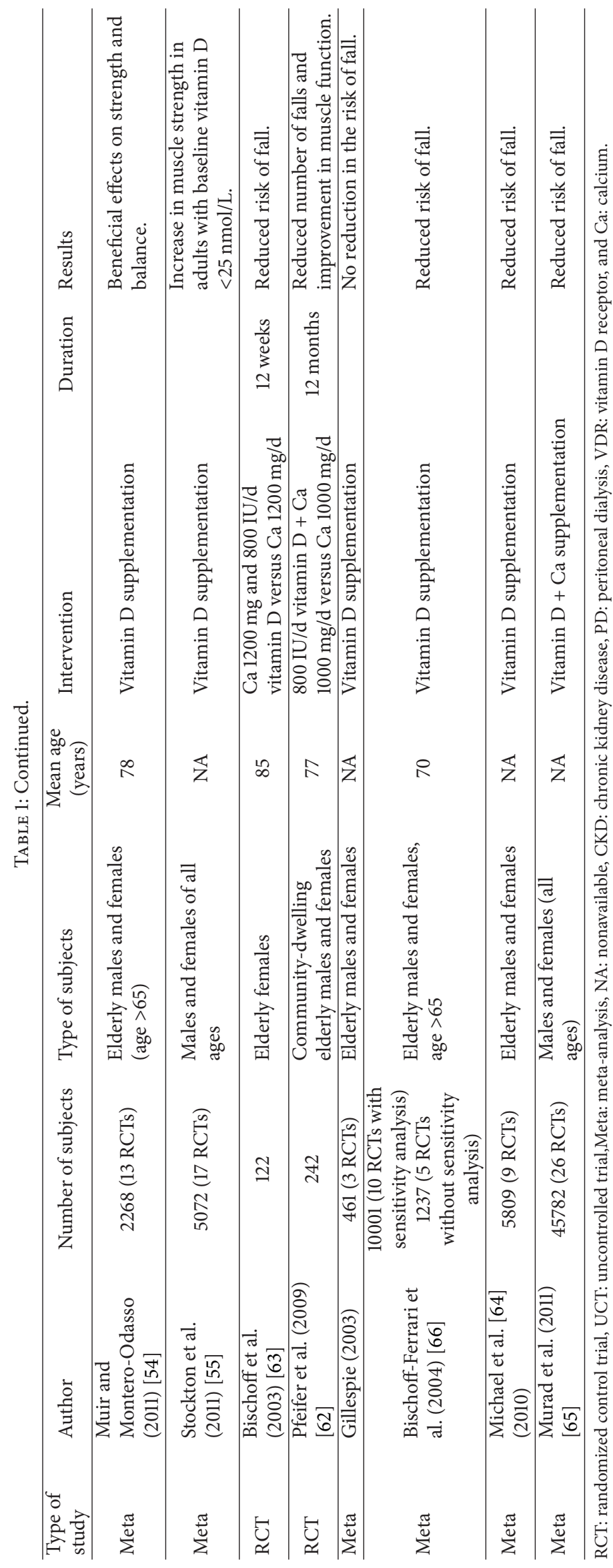


lack of clinical effect may be explained by the inability of high intermittent doses of vitamin D to maintain high serum levels for a sustained period, as suggested by Gupta et al. [44].

The meta-analysis from Muir and Montero-Odasso, which pooled results from 13 RCTs in individuals older than 60 years old, supported a small benefit of daily vitamin D supplementation (800 IU to $1000 \mathrm{IU}$ per day) for muscle strength and balance [54]. However, another meta-analysis by Stockton et al. looking at 17 RCTs in individuals of all ages including younger subjects only showed a benefit in muscle strength in subjects with vitamin D serum levels below $25 \mathrm{nmol} / \mathrm{L}$ at baseline [55].

Whether 1,25 vitamin D is also effective to improve muscle function has been insufficiently investigated. A prospective uncontrolled trial, not meeting the criteria of our search but including 2000 elderly subjects (mean age of 75 years, $80 \%$ females), showed that a daily supplementation of $1 \mathrm{mcg}$ of alfacalcidol leads to significant improvements of the TUG, chair rising test, and tandem gait tests, used as surrogates of muscle performance and risk of fall [56].

Overall, data from RCT and meta-analysis support a positive effect of daily vitamin D supplementation on muscle function, especially in older individuals with vitamin $\mathrm{D}$ insufficiency/deficiency at baseline. A daily dose of $1000 \mathrm{UI}$ appears to be sufficient to obtain significant improvements. In contrast, large intermittent doses of vitamin D do not appear to be efficient at improving muscle strength.

\section{Relationship between Vitamin D Status, Muscle, and Falls}

The known association of vitamin $\mathrm{D}$ insufficiency and increased risk of falls and fractures in the elderly [50, 51, 5759] was thought to depend on bone remodeling via the rise of PTH [60]. However, current understanding has highlighted the importance of a direct effect of vitamin $\mathrm{D}$ on muscle strength and function [21] to explain this association. Because vitamin $\mathrm{D}$ has an effect on type 2 muscle fibers, it was tempting to speculate a protective effect of vitamin $\mathrm{D}$ on falls, via improvement in muscle function. A high number of RCTs have investigated whether vitamin D supplementation had an effect on muscle function and the incidence of falls. A Cochrane review published in 2003 [61] evaluated the efficacy of supplementation with vitamin D analogs, either alone or with calcium as cosupplementation at preventing falls. The overall analysis of vitamin $\mathrm{D}$ versus control found no significant difference in the rate of falls when applied to unselected community-dwelling and hospitalized elderly subjects (RR 0.87, 95\% CI 0.70-1.08). In contrast, in more recent studies, benefits of vitamin $\mathrm{D}$ supplementation were significant. Pfeifer et al. demonstrated a reduction in falls of 27 and $39 \%$ at one year and 20 months, respectively, in community-dwelling seniors supplemented with $800 \mathrm{IU}$ vitamin $\mathrm{D}$ and calcium daily versus with calcium only [62]. This reduction in falls was correlated with an improvement in quadriceps strength and an improvement in the TUG test. These results are consistent with the study of Bischoff et al. who showed a $49 \%$ reduction of falls in elderly women from a geriatric ward supplemented with 800 IU per day of vitamin $\mathrm{D}$ [63]. In the same period, results from 3 meta-analyses demonstrate a significant reduction in the odd ratio of falls in individuals supplemented with vitamin D [64-66].

Figure 2 shows the effects of vitamin D on muscle function, gait, and falls. Table 1 summarizes the studies which investigated the clinical effects of vitamin $\mathrm{D}$ on muscle strength, function, and the risk of falls. The most recent report of the Endocrine Society Clinical Practice Guidelines recommends vitamin $\mathrm{D}$ supplementation depending on age and clinical circumstances, in particular in order to prevent falls in populations at risk [15]. However, a recent paper from the Institute of Medicine from the United States questioned the effect of vitamin $\mathrm{D}$ supplementation on extraskeletal outcomes [67], in particular in the setting of falls, arguing that the meta-analysis of Bischoff-Ferrari et al. provided misleading conclusions, that is, a vitamin D-associated decrease of $22 \%$ in the risk of falls, due to heterogeneity considerations in the 5 RCTs considered [66].

\section{A Link between Vitamin D and Frailty?}

The term "frailty" is becoming more and more popular in geriatric medicine. However, its definition is vague. The Oxford dictionary defined it by "the condition of being weak and delicate." A more precise definition is given by Fried who defined frailty as "a biologic syndrome of decrease reserve and resistance to stressors that results from cumulative declines across multiple physiologic systems and causes vulnerability to adverse outcomes [68]." Criteria of the frail phenotype have been described in order to translate the above theoretical definition into clinical indicators [68]. These are as follows: unintentional weight loss, self-reported exhaustion, weakness (grip strength), slow walking speed, and low physical activity. According to these clinical criteria, 3 phenotypes have been identified: robust: 0 criteria; prefrail: between 1 and 2 criteria; frail: 3 or more criteria. The majority of these criteria are related to locomotion and physical strength. Thus, it looks readily conceivable that hypovitaminosis $\mathrm{D}$ may lead to frailty, through negative effects on muscle strength and/or function.

The association between vitamin D status and frailty has been studied in a number of observational studies. Data from an observational study from Hirani et al. which included 1659 community-dwelling men, with a $10 \%$ prevalence of frailty, showed that low vitamin D levels were independently associated with frailty [69]. A similar association was found by Tajar et al. in another cohort of elderly men. Subjects with vitamin D levels $<50 \mathrm{nmol} / \mathrm{L}$ had an odd ratio of 2,37 of being classified into the "frail" versus the "robust" phenotype [70]. Using data from the third National Health and Nutrition Survey (NHANES), Wilhelm-Leen et al. found an association between frailty and a low vitamin $\mathrm{D}$ status in both elderly men and women, with overall 4-fold increase in the odd ratio of frailty [71]. Vitamin D not only is associated with frailty but also appears to be associated with an increased risk to develop frailty over time in women. In a prospective study including elderly women (age $>69$ years), nonfrail women at baseline but displaying a vitamin $\mathrm{D}$ level of less than $50 \mathrm{nmol} / \mathrm{L}$ had 


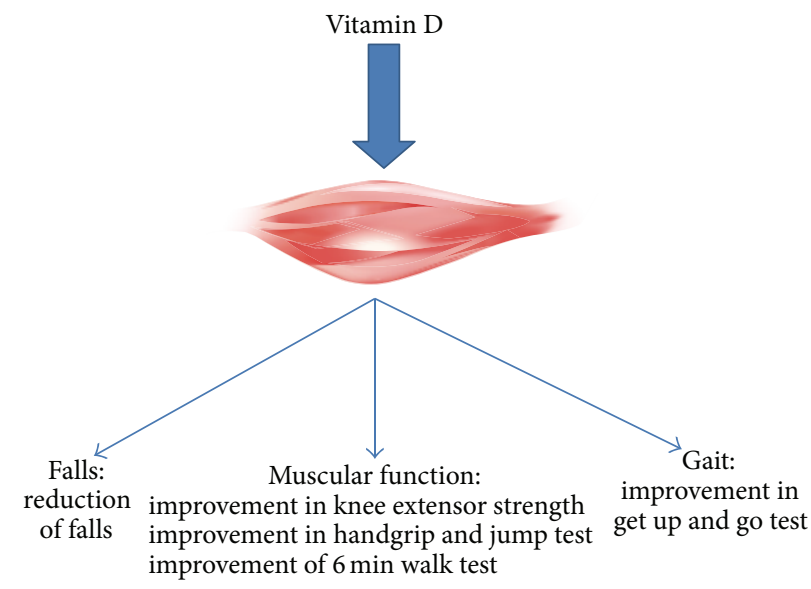

FIGURE 2: Clinical effects of vitamin D on muscles gait and falls.

a higher risk of becoming frail during the 4.5 years of followup than women with a higher level of vitamin D [72]. In a study from patients with cardiac insufficiency, Boxer et al. found an association between low vitamin $\mathrm{D}$ levels and the frail phenotype. In particular, vitamin D levels and the result of the 6-minute walking test were correlated [73]. In cardiac diseases, this functional test is known to predict survival [74]. Thus, low vitamin D is hypothesized to link with mortality in this setting. A prospective study including 4000 individuals (1943 men and 2788 women, mean age: 70), followed up to 12 years, indeed found a link between lower levels of vitamin $\mathrm{D}$, frailty, and mortality. An assessment of vitamin $\mathrm{D}$ status and the physical phenotype (robust/prefrail/frail) were performed at baseline [75].

Mortality was positively associated with frailty. Frail individuals with a low vitamin D level were at increased risk (hazard ratio of 2.98) of death during the follow-up compared to robust individuals with a high level of vitamin D. Thus, overall, a clear association between vitamin D level and frailty has been demonstrated. Furthermore, interplays between vitamin D status, frailty, and mortality appear plausible. Whether vitamin D supplementation in frail subjects may reduce mortality is challenging and needs to be investigated in the future.

\section{Conclusion}

Consistent relationships exist between vitamin $\mathrm{D}$ status and muscle function, especially in the elderly frail patient. There is evidence that hypovitaminosis $\mathrm{D}$ is associated with a decline in muscle function. Vitamin D supplementation has beneficial effects on muscle strength, balance, and gait in diverse settings including adolescents, the elderly, and CKD patients. However, the effects of vitamin $\mathrm{D}$ on the prevention of falls are still a matter of debate due to conflicting interpretation of data. Differences in the dose of supplementation, type of vitamin $\mathrm{D}$, and discrepancies in the threshold to define vitamin $\mathrm{D}$ deficiency/insufficiency may partly explain these disagreements. A low vitamin D status is consistently associated with frailty. Considering that vitamin
D supplementation is safe and inexpensive, it is worthy to recommend vitamin D supplementation in patients at risk for falls, such as elderly patients, nursing home residents, frail patients with gait and balance and visual impairments, and patients with chronic diseases. These patients are most likely to have low levels of vitamin D and muscle loss/dysfunction, thus justifying supplementation independent of a putative effect on the prevention of falls.

\section{Conflict of Interests}

The authors declare that there is no conflict of interests regarding the publication of this paper.

\section{References}

[1] S. J. Marx, U. A. Liberman, and C. Eil, "Calciferols: actions and deficiencies in action," Vitamins \& Hormones, vol. 40, pp. 235308, 1983.

[2] E. M. Costa, H. M. Blau, and D. Feldman, "1,25-Dihydroxyvitamin $\mathrm{D}_{3}$ receptors and hormonal responses in cloned human skeletal muscle cells," Endocrinology, vol. 119, no. 5, pp. 22142220, 1986.

[3] J. Valtueña Santamaría, L. Gracia-Marco, I. Huybrechts et al., "Cardiorespiratory fitness in males, and upper limbs muscular strength in females, are positively related with 25 -hydroxyvitamin D plasma concentrations in European adolescents: the HELENA Study," QJM, vol. 106, no. 9, pp. 809-821, 2013.

[4] M. F. Holick, "Sunlight and vitamin D for bone health and prevention of autoimmune diseases, cancers, and cardiovascular disease," The American Journal of Clinical Nutrition, vol. 80, no. 6, supplement, pp. 1678S-1688S, 2004.

[5] C. Annweiler, G. Allali, P. Allain et al., "Vitamin D and cognitive performance in adults: a systematic review," European Journal of Neurology, vol. 16, no. 10, pp. 1083-1089, 2009.

[6] S. Cohen, J. A. Nathan, and A. L. Goldberg, "Muscle wasting in disease: molecular mechanisms and promising therapies," Nature Reviews Drug Discovery, vol. 14, no. 1, pp. 58-74, 2014.

[7] S. Yoshikawa, T. Nakamura, H. Tanabe, and T. Imamura, "Osteomalacic myopathy," Endocrinologia Japonica, vol. 26, supplement, pp. 65-72, 1979. 
[8] B. Hamilton, "Vitamin D and human skeletal muscle," Scandinavian Journal of Medicine and Science in Sports, vol. 20, no. 2, pp. 182-190, 2010.

[9] L. Y. Matsuoka, L. Ide, J. Wortsman, J. A. MacLaughlin, and M. F. Holick, "Sunscreens suppress cutaneous vitamin D3 synthesis," The Journal of Clinical Endocrinology \& Metabolism, vol. 64, no. 6, pp. 1165-1168, 1987.

[10] L. Plantalech, P. Knoblovits, E. Cambiazzo et al., "Hypervitaminosis D in institutionalized elderly in Buenos Aires," Medicina B: Aires, vol. 57, no. 1, pp. 29-35, 1997.

[11] T. Songpatanasilp, L.-O. Chailurkit, A. Nichachotsalid, and M. Chantarasorn, "Combination of alfacalcidol with calcium can improve quadriceps muscle strength in elderly ambulatory Thai women who have hypovitaminosis D: a randomized controlled trial," Journal of the Medical Association of Thailand, vol. 92, supplement 5, pp. S30-S41, 2009.

[12] M. J. McKenna and R. Freaney, "Secondary hyperparathyroidism in the elderly: means to defining hypovitaminosis D," Osteoporosis International, vol. 8, supplement 2, pp. S3-S6, 1998.

[13] M.-C. Chapuy, P. Preziosi, M. Maamer et al., "Prevalence of vitamin D insufficiency in an adult normal population," Osteoporosis International, vol. 7, no. 5, pp. 439-443, 1997.

[14] M. González-Gross, J. Valtueña, C. Breidenassel et al., "Vitamin D status among adolescents in Europe: the healthy lifestyle in Europe by nutrition in adolescence study," British Journal of Nutrition, vol. 107, no. 5, pp. 755-764, 2012.

[15] M. F. Holick, N. C. Binkley, H. A. Bischoff-Ferrari et al., "Evaluation, treatment, and prevention of vitamin D deficiency: an endocrine society clinical practice guideline," Journal of Clinical Endocrinology and Metabolism, vol. 96, no. 7, pp. 19111930, 2011.

[16] H. A. Bischoff-Ferrari, E. Giovannucci, W. C. Willett, T. Dietrich, and B. Dawson-Hughes, "Estimation of optimal serum concentrations of 25-hydroxyvitamin D for multiple health outcomes," The American Journal of Clinical Nutrition, vol. 84, no. 1, pp. 18-28, 2006.

[17] B. Oliveri, L. Plantalech, A. Bagur et al., "High prevalence of vitamin D insufficiency in healthy elderly people living at home in Argentina," European Journal of Clinical Nutrition, vol. 58, no. 2, pp. 337-342, 2004.

[18] P. Bettica, M. Bevilacqua, T. Vago, and G. Norbiato, "High prevalence of hypovitaminosis D among free-living postmenopausal women referred to an osteoporosis outpatient clinic in Northern Italy for initial screening," Osteoporosis International, vol. 9, no. 3, pp. 226-229, 1999.

[19] H. Reichel, H. P. Koeffler, and A. W. Normal, "The role of the vitamin D endocrine system in health and disease," The New England Journal of Medicine, vol. 320, no. 15, pp. 980-991, 1989.

[20] R. U. Simpson, G. A. Thomas, and A. J. Arnold, "Identification of 1,25-dihydroxyvitamin D3 receptors and activities in muscle," The Journal of Biological Chemistry, vol. 260, no. 15, pp. 88828891, 1985.

[21] L. Ceglia and S. S. Harris, "Vitamin D and its role in skeletal muscle," Calcified Tissue International, vol. 92, no. 2, pp. 151-162, 2013.

[22] R. Boland, A. R. de Boland, E. Ritz, and W. Hasselbach, "Effect of 1,25-dihydroxycholecalciferol on sarcoplasmic reticulum calcium transport in strontium-fed chicks," Calcified Tissue International, vol. 35, no. 1, pp. 190-194, 1983.
[23] D. Lila, Z. Susana, and B. Ricardo, "Induction of a calbindinD9K-like protein in avian muscle cells by 1,25-dihydroxyvitamin D3," Biochemistry and Molecular Biology International, vol. 32, no. 5, pp. 859-867, 1994.

[24] E. R. Barton-Davis, D. I. Shoturma, A. Musaro, N. Rosenthal, and H. Lee Sweeney, "Viral mediated expression of insulin-like growth factor I blocks the aging-related loss of skeletal muscle function," Proceedings of the National Academy of Sciences of the United States of America, vol. 95, no. 26, pp. 15603-15607, 1998.

[25] I. Nemere and D. Larsson, " $1,25(\mathrm{OH})_{2}$-vitamin $\mathrm{D}_{3}$ induces translocation of the vitamin $\mathrm{D}$ receptor (VDR) to the plasma membrane in skeletal muscle cells," Journal of Cellular Biochemistry, vol. 86, no. 1, pp. 128-135, 2002.

[26] I. Nemere, Z. Schwartz, H. Pedrozo, V. L. Sylvia, D. D. Dean, and B. D. Boyan, "Identification of a membrane receptor for 1,25-dihydroxyvitamin D3 which mediates rapid activation of protein kinase C," Journal of Bone and Mineral Research, vol. 13, no. 9, pp. 1353-1359, 1998.

[27] L. Ceglia, S. Niramitmahapanya, M. da Silva Morais et al., "A Randomized study on the effect of vitamin $\mathrm{d} 3$ supplementation on skeletal muscle morphology and vitamin d receptor concentration in older women," Journal of Clinical Endocrinology and Metabolism, vol. 98, no. 12, pp. E1927-E1935, 2013.

[28] P. Geusens, C. Vandevyver, J. Vanhoof, J.-J. Cassiman, S. Boonen, and J. Raus, "Quadriceps and grip strength are related to vitamin D receptor genotype in elderly nonobese women," Journal of Bone and Mineral Research, vol. 12, no. 12, pp. 20822088, 1997.

[29] D. K. Houston, M. Cesari, L. Ferrucci et al., "Association between vitamin $\mathrm{D}$ status and physical performance: the InCHIANTI study," Journals of Gerontology Series A: Biological Sciences and Medical Sciences, vol. 62, no. 4, pp. 440-446, 2007.

[30] S. R. Mastaglia, M. Seijo, D. Muzio, J. Somoza, M. Nuñez, and B. Oliveri, "Effect of vitamin D nutritional status on muscle function and strength in healthy women aged over sixty-five years," Journal of Nutrition, Health and Aging, vol. 15, no. 5, pp. 349-354, 2011.

[31] M. Zamboni, E. Zoico, P. Tosoni et al., "Relation between vitamin $\mathrm{D}$, physical performance, and disability in elderly persons," Journals of Gerontology A-Biological Sciences and Medical Sciences, vol. 57, no. 1, pp. M7-M11, 2002.

[32] I. S. Wicherts, N. M. van Schoor, A. J. P. Boeke et al., "Vitamin D status predicts physical performance and its decline in older persons," Journal of Clinical Endocrinology and Metabolism, vol. 92, no. 6, pp. 2058-2065, 2007.

[33] M. Visser, D. J. H. Deeg, P. Lips, and Longitudinal Aging Study, "Low vitamin D and high parathyroid hormone levels as determinants of loss of muscle strength and muscle mass (sarcopenia): the Longitudinal Aging Study Amsterdam," Journal of Clinical Endocrinology and Metabolism, vol. 88, no. 12, pp. 57665772, 2003

[34] N. D. A. Boyé, C. Oudshoorn, N. van der Velde et al., "Vitamin $\mathrm{D}$ and physical performance in older men and women visiting the emergency department because of a fall: data from the improving medication prescribing to reduce risk of FALLs (IMPROveFALL) study," Journal of the American Geriatrics Society, vol. 61, no. 11, pp. 1948-1952, 2013.

[35] E. D. Toffanello, E. Perissinotto, G. Sergi et al., "Vitamin D and physical performance in elderly subjects: the Pro.V.A study," PLoS ONE, vol. 7, no. 4, Article ID e34950, 2012.

[36] P. R. von Hurst, C. Conlon, and A. Foskett, "Vitamin D status predicts hand-grip strength in young adult women living in 
Auckland, New Zealand," Journal of Steroid Biochemistry and Molecular Biology, vol. 136, no. 1, pp. 330-332, 2013.

[37] A. S. Grimaldi, B. A. Parker, J. A. Capizzi et al., "25(OH) vitamin $\mathrm{D}$ is associated with greater muscle strength in healthy men and women," Medicine and Science in Sports and Exercise, vol. 45, no. 1, pp. 157-162, 2013.

[38] P. L. Gordon, J. W. Doyle, and K. L. Johansen, "Association of 1,25-dihydroxyvitamin $\mathrm{D}$ levels with physical performance and thigh muscle cross-sectional area in chronic kidney disease stage 3 and 4," Journal of Renal Nutrition, vol. 22, no. 4, pp. 423433, 2012.

[39] H. Taskapan, O. Baysal, D. Karahan, B. Durmus, Z. Altay, and O. Ulutas, "Vitamin D and muscle strength, functional ability and balance in peritoneal dialysis patients with vitamin D deficiency," Clinical Nephrology, vol. 76, no. 2, pp. 110-116, 2011.

[40] N. Zahed, S. Chehrazi, and K. Falaknasi, "The evaluation of relationship between vitamin $\mathrm{D}$ and muscle power by micro manual muscle tester in end-stage renal disease patients," Saudi Journal of Kidney Diseases and Transplantation, vol. 25, no. 5, pp. 998-1003, 2014.

[41] P. Pramyothin, S. Techasurungkul, J. Lin et al., "Vitamin D status and falls, frailty, and fractures among postmenopausal Japanese women living in Hawaii," Osteoporosis International, vol. 20, no. 11, pp. 1955-1962, 2009.

[42] L. Ceglia, G. R. Chiu, S. S. Harris, and A. B. Araujo, "Serum 25hydroxyvitamin D concentration and physical function in adult men," Clinical Endocrinology, vol. 74, no. 3, pp. 370-376, 2011.

[43] C. Matheï, G. van Pottelbergh, B. Vaes, W. Adriaensen, D. Gruson, and J.-M. Degryse, "No relation between vitamin D status and physical performance in the oldest old: results from the belfrail study," Age and Ageing, vol. 42, no. 2, pp. 186-190, 2013.

[44] R. Gupta, U. Sharma, N. Gupta et al., "Effect of cholecalciferol and calcium supplementation on muscle strength and energy metabolism in vitamin D-deficient Asian Indians: a randomized, controlled trial," Clinical Endocrinology, vol. 73, no. 4, pp. 445-451, 2010.

[45] K. Zhu, N. Austin, A. Devine, D. Bruce, and R. L. Prince, "A randomized controlled trial of the effects of vitamin D on muscle strength and mobility in older women with vitamin $\mathrm{d}$ insufficiency," Journal of the American Geriatrics Society, vol. 58, no. 11, pp. 2063-2068, 2010.

[46] K. A. Ward, G. Das, S. A. Roberts et al., "A randomized, controlled trial of vitamin D supplementation upon musculoskeletal health in postmenarchal females," Journal of Clinical Endocrinology and Metabolism, vol. 95, no. 10, pp. 4643-4651, 2010.

[47] M. A. Wyon, Y. Koutedakis, R. Wolman, A. M. Nevill, and N. Allen, "The influence of winter vitamin D supplementation on muscle function and injury occurrence in elite ballet dancers: a controlled study," Journal of Science and Medicine in Sport, vol. 17, no. 1, pp. 8-12, 2014.

[48] A. M. Kenny, B. Biskup, B. Robbins, G. Marcella, and J. A. Burleson, "Effects of vitamin D supplementation on strength, physical function, and health perception in older, communitydwelling men," Journal of the American Geriatrics Society, vol. 51, no. 12, pp. 1762-1767, 2003.

[49] P. Lips, N. Binkley, M. Pfeifer et al., “Once-weekly dose of 8400 IU vitamin D3 compared with placebo: effects on neuromuscular function and tolerability in older adults with vitamin D insufficiency," American Journal of Clinical Nutrition, vol. 91, no. 4, pp. 985-991, 2010.
[50] K. A. Faulkner, J. A. Cauley, J. M. Zmuda et al., "Higher 1,25-dihydroxyvitamin $\mathrm{D}_{3}$ concentrations associated with lower fall rates in older community-dwelling women," Osteoporosis International, vol. 17, no. 9, pp. 1318-1328, 2006.

[51] T. Suzuki, J. Kwon, H. Kim et al., "Low serum 25-hydroxyvitamin D levels associated with falls among Japanese communitydwelling elderly," Journal of Bone and Mineral Research, vol. 23, no. 8, pp. 1309-1317, 2008.

[52] P. Glendenning, K. Zhu, C. Inderjeeth, P. Howat, J. R. Lewis, and R. L. Prince, "Effects of three-monthly oral 150,000 IU cholecalciferol supplementation on falls, mobility, and muscle strength in older postmenopausal women: a randomized controlled trial," Journal of Bone and Mineral Research, vol. 27, no. 1, pp. 170-176, 2012.

[53] R. Goswami, M. Vatsa, V. Sreenivas et al., "Skeletal muscle strength in young Asian Indian females after vitamin D and calcium supplementation: a double-blind randomized controlled clinical trial," Journal of Clinical Endocrinology and Metabolism, vol. 97, no. 12, pp. 4709-4716, 2012.

[54] S. W. Muir and M. Montero-Odasso, "Effect of vitamin D supplementation on muscle strength, gait and balance in older adults: a systematic review and meta-analysis," Journal of the American Geriatrics Society, vol. 59, no. 12, pp. 2291-2300, 2011.

[55] K. A. Stockton, K. Mengersen, J. D. Paratz, D. Kandiah, and K. L. Bennell, "Effect of vitamin D supplementation on muscle strength: a systematic review and meta-analysis," Osteoporosis International, vol. 22, no. 3, pp. 859-871, 2011.

[56] E. Schacht and J. D. Ringe, "Alfacalcidol improves muscle power, muscle function and balance in elderly patients with reduced bone mass," Rheumatology International, vol. 32, no. 1, pp. 207215, 2012.

[57] P. Gerdhem, K. A. M. Ringsberg, K. J. Obrant, and K. Akesson, "Association between 25- hydroxy vitamin D levels, physical activity, muscle strength and fractures in the prospective population-based OPRA Study of Elderly Women," Osteoporosis International, vol. 16, no. 11, pp. 1425-1431, 2005.

[58] M. B. Snijder, N. M. van Schoor, S. M. F. Pluijm, R. M. van Dam, M. Visser, and P. Lips, "Vitamin D status in relation to one-year risk of recurrent falling in older men and women," The Journal of Clinical Endocrinology \& Metabolism, vol. 91, no. 8, pp. 29802985, 2006.

[59] P. Lips, "Vitamin D deficiency and secondary hyperparathyroidism in the elderly: consequences for bone loss and fractures and therapeutic implications," Endocrine Reviews, vol. 22, no. 4, pp. 477-501, 2001.

[60] M. Brazier, S. Kamel, M. Maamer et al., "Markers of bone remodeling in the elderly subject: effects of vitamin D insufficiency and its correction," Journal of Bone and Mineral Research, vol. 10, no. 11, pp. 1753-1761, 1995.

[61] L. D. Gillespie, M. C. Robertson, W. J. Gillespie et al., "Interventions for preventing falls in older people living in the community," Cochrane Database of Systematic Reviews, vol. 9, Article ID CD007146, 2012.

[62] M. Pfeifer, B. Begerow, H. W. Minne, K. Suppan, A. FahrleitnerPammer, and H. Dobnig, "Effects of a long-term vitamin $\mathrm{D}$ and calcium supplementation on falls and parameters of muscle function in community-dwelling older individuals," Osteoporosis International, vol. 20, no. 2, pp. 315-322, 2009.

[63] H. A. Bischoff, H. B. Stähelin, W. Dick et al., "Effects of vitamin D and calcium supplementation on falls: a randomized controlled trial," Journal of Bone and Mineral Research, vol. 18, no. 2, pp. 343-351, 2003. 
[64] Y. L. Michael, E. P. Whitlock, J. S. Lin, R. Fu, E. A. O'Connor, and R. Gold, "Primary care-relevant interventions to prevent falling in older adults: a systematic evidence review for the U.S. Preventive Services Task Force," Annals of Internal Medicine, vol. 153, no. 12, pp. 815-825, 2010.

[65] M. H. Murad, K. B. Elamin, N. O. Abu Elnour et al., "The effect of vitamin D on falls: a systematic review and meta-analysis," The Journal of Clinical Endocrinology \& Metabolism, vol. 96, no. 10, pp. 2997-3006, 2011.

[66] H. A. Bischoff-Ferrari, B. Dawson-Hughes, W. C. Willett et al., "Effect of vitamin D on falls: a meta-analysis," The Journal of the American Medical Association, vol. 291, no. 16, pp. 1999-2006, 2004.

[67] A. C. Ross, J. E. Manson, S. A. Abrams et al., "The 2011 report on dietary reference intakes for calcium and vitamin $\mathrm{D}$ from the Institute of Medicine: what clinicians need to know," Journal of Clinical Endocrinology and Metabolism, vol. 96, no. 1, pp. 53-58, 2011.

[68] L. P. Fried, C. M. Tangen, J. Walston et al., "Frailty in older adults: evidence for a phenotype," The Journals of Gerontology Series A: Biological Sciences and Medical Sciences, vol. 56, no. 3, pp. M146-M156, 2001.

[69] V. Hirani, R. G. Cumming, V. Naganathan et al., "Associations between serum 25-hydroxyvitamin D concentrations and multiple health conditions, physical performance measures, disability, and all-cause mortality: the concord health and ageing in men project," Journal of the American Geriatrics Society, vol. 62, no. 3, pp. 417-425, 2014.

[70] A. Tajar, D. M. Lee, S. R. Pye et al., "The association of frailty with serum 25-hydroxyvitamin $\mathrm{d}$ and parathyroid hormone levels in older european men," Age and Ageing, vol. 42, no. 3, pp. 352-359, 2013.

[71] E. R. Wilhelm-Leen, Y. N. Hall, I. H. Deboer, and G. M. Chertow, "Vitamin D deficiency and frailty in older Americans," Journal of Internal Medicine, vol. 268, no. 2, pp. 171-180, 2010.

[72] K. E. Ensrud, S. K. Ewing, L. Fredman et al., "Circulating 25hydroxyvitamin D levels and frailty status in older women," Journal of Clinical Endocrinology and Metabolism, vol. 95, no. 12, pp. 5266-5273, 2010.

[73] R. S. Boxer, D. A. Dauser, S. J. Walsh, W. D. Hager, and A. M. Kenny, "The association between vitamin D and inflammation with the 6-minute walk and frailty in patients with heart failure," Journal of the American Geriatrics Society, vol. 56, no. 3, pp. 454$461,2008$.

[74] L. Ingle, J. G. Cleland, and A. L. Clark, “The long-term prognostic significance of 6-minute walk test distance in patients with chronic heart failure," BioMed Research International, vol. 2014, Article ID 505969, 7 pages, 2014.

[75] E. Smit, C. J. Crespo, Y. Michael et al., "The effect of vitamin D and frailty on mortality among non-institutionalized US older adults," European Journal of Clinical Nutrition, vol. 66, no. 9, pp. 1024-1028, 2012. 


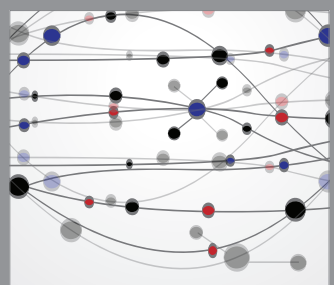

The Scientific World Journal
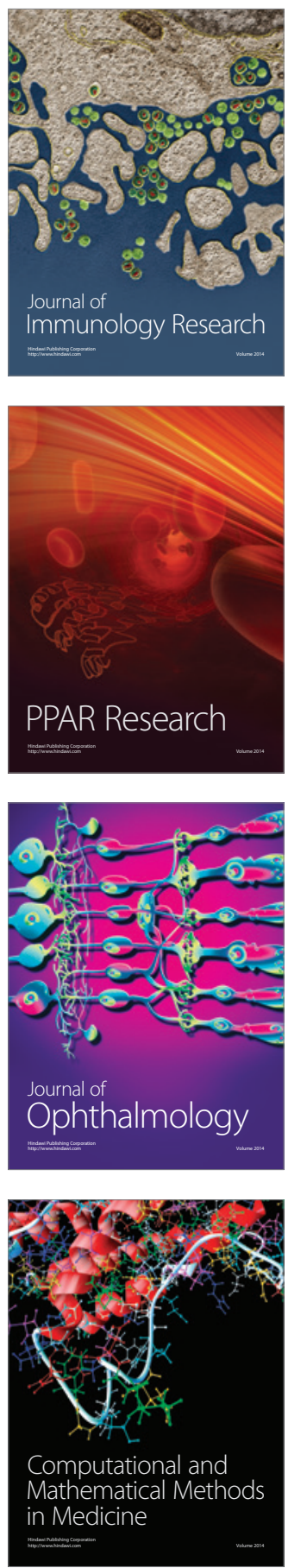

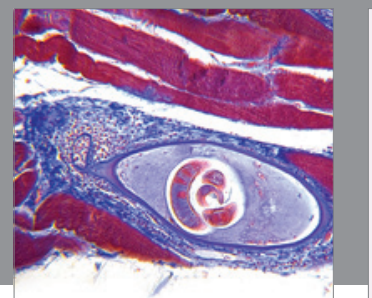

Gastroenterology

Research and Practice
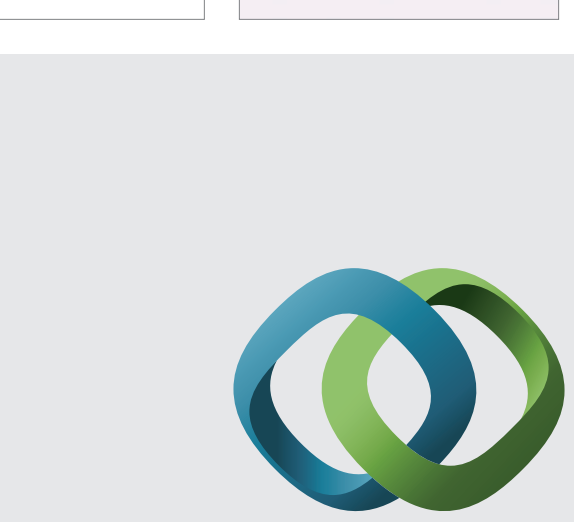

\section{Hindawi}

Submit your manuscripts at

http://www.hindawi.com
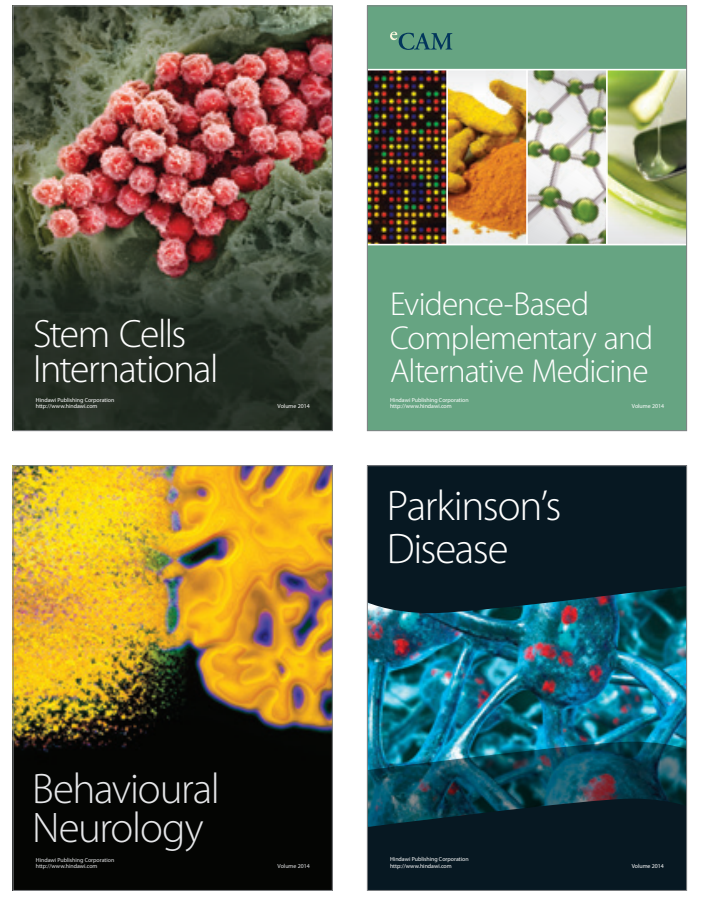
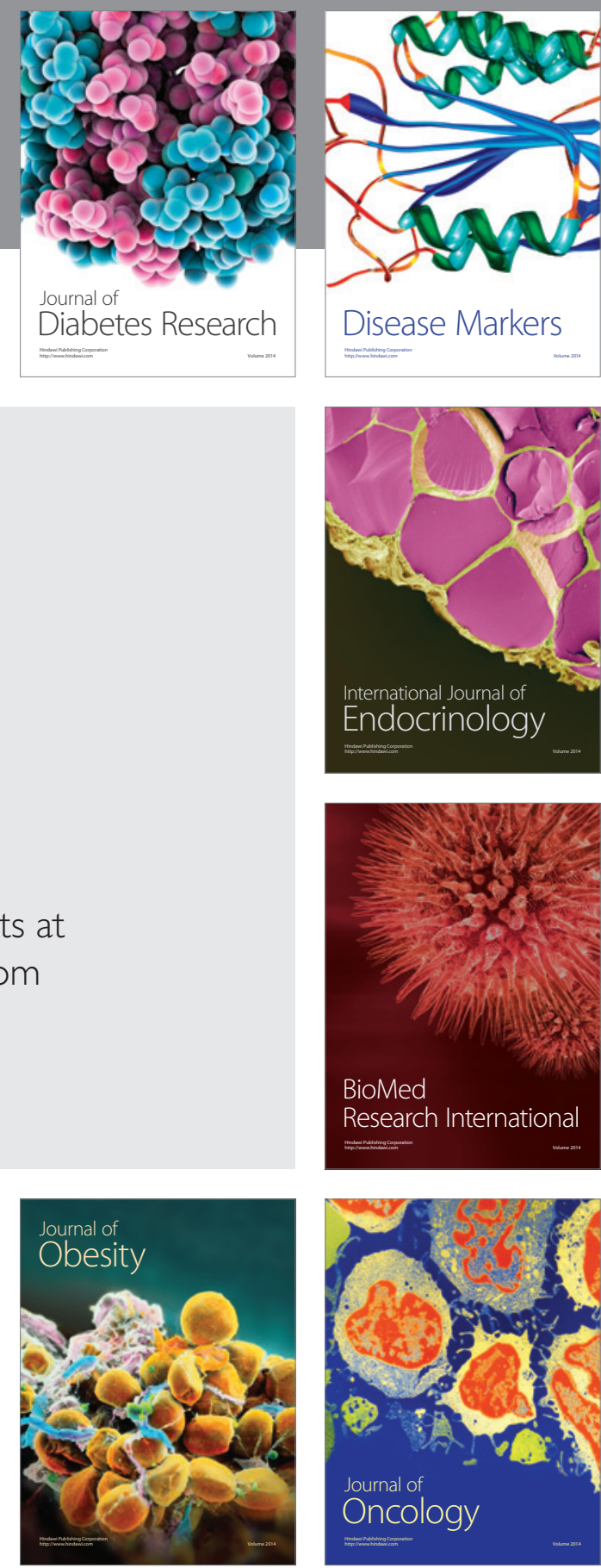

Disease Markers
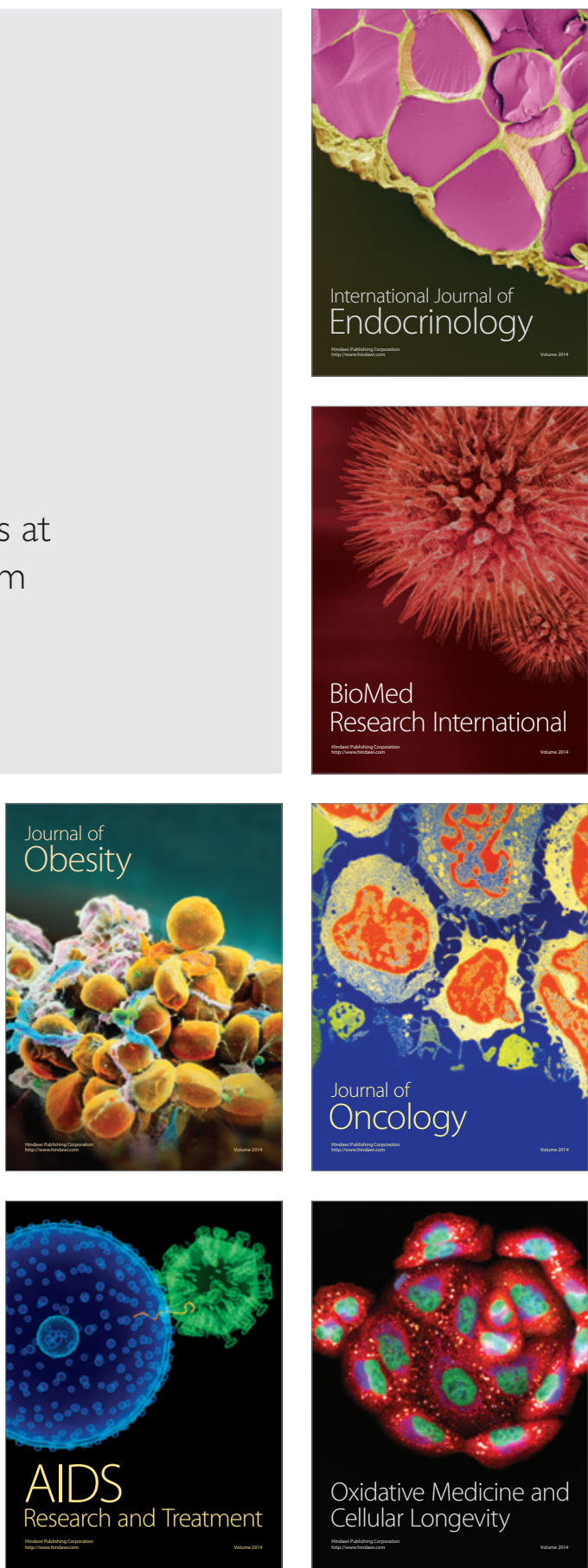